\title{
The VHL-dependent regulation of microRNAs in renal cancer
}

\author{
Calida S Neal ${ }^{1,2}$, Michael Z Michael ${ }^{2}$, Lesley H Rawlings ${ }^{3}$, Mark B Van der Hoek ${ }^{4}$, Jonathan M Gleadle ${ }^{1 *}$
}

\begin{abstract}
Background: The commonest histological type of renal cancer, clear cell renal cell carcinoma (cc RCC), is associated with genetic and epigenetic changes in the von Hippel-Lindau (VHL) tumour suppressor. VHL inactivation leads to induction of hypoxia-inducible factors (HIFs) and a hypoxic pattern of gene expression. Differential levels of specific microRNAs (miRNAs) are observed in several tumours when compared to normal tissue. Given the central role of $\mathrm{VHL}$ in renal cancer formation, we examined the $\mathrm{VHL}$-dependent regulation of miRNAs in renal cancer.

Methods: VHL-dependent miRNA expression in CC RCC was determined by microarray analysis of renal cell line RCC4 with mutated VHL (RCC4-VHL) and reintroduced wild-type VHL (RCC4 + VHL). Five miRNAs highly upregulated in RCC4 + VHL and five miRNAs highly downregulated in RCC4 + VHL were studied further, in addition to miR-210, which is regulated by the HIF-VHL system. miRNA expression was also measured in $31 \mathrm{cc}$ RCC tumours compared to adjacent normal tissue.

Results: A significant increase in miR-210, miR-155 and miR-21 expression was observed in the tumour tissue. miR210 levels also showed a correlation with a HIF-regulated mRNA, carbonic anhydrase IX (CAIX), and with VHL mutation or promoter methylation. An inverse correlation was observed between miR-210 expression and patient survival, and a putative target of miR-210, iron-sulfur cluster assembly protein (ISCU1/2), shows reciprocal levels of mRNA expression in the tumours.

Conclusions: We have identified VHL-regulated miRNAs and found that for some the regulation is HIF-dependent and for others it is HIF-independent. This pattern of regulation was also seen in renal cancer tissue for several of these miRNAs (miR-210, miR-155, let-7i and members of the miR-17-92 cluster) when compared with normal tissue. miR-210 showed marked increases in expression in renal cancer and levels correlated with patient survival. The inverse correlation between miR-210 levels and ISCU1/2 provides support for the hypothesis that ISCU1/2 is a target of miR-210 and that it may contribute to the anaerobic respiration seen in renal (and other) tumours. See Commentary: http://www.biomedcentral.com/1741-7015/8/65
\end{abstract}

\section{Background}

Renal cell carcinoma accounts for 2-3\% of malignant diseases in adults, with an increasing worldwide incidence of over 200,000 new cases and 100,000 deaths per year [1]. The understanding of the pathogenesis of the commonest histological type, clear cell renal cell carcinoma (cc RCC), has been considerably advanced by the recognition that the gene encoding the von Hippel-Lindau (VHL) protein is defective in patients with VHL

\footnotetext{
* Correspondence: jonathan.gleadle@health.sa.gov.au

'Renal Unit, School of Medicine, Flinders University, Flinders Medical Centre, Adelaide, Australia

Full list of author information is available at the end of the article
}

disease and in the majority of sporadic cc RCCs resulting in activation of a hypoxic pattern of gene expression $[2,3]$. The exposure of cells to hypoxia normally leads to the coordinated regulation of many genes by the transcription factor hypoxia-inducible factor (HIF). In this process, the VHL protein functions as an E3 ubiquitin ligase which recognises and binds to two specific hydroxyprolyl residues in HIF- $1 \alpha$ and HIF- $2 \alpha$ and facilitates ubiquitination, leading to rapid proteasomal degradation $[4,5]$. In the presence of oxygen, HIF- $\alpha$ molecules undergo prolyl hydroxylation catalysed by three homologous 2-oxoglutarate-dependent dioxygenases, PHD1, PHD2 and PHD3 [6]. The protein products of this 
broad array of hypoxically regulated genes have critical roles in processes such as energy metabolism, angiogenesis, growth and apoptosis $[5,7,8]$. The majority of cc RCCs exhibit VHL mutations and/or silencing by methylation, which leads to enhanced HIF action and a hypoxic pattern of gene expression [2,3]. VHL also has a number of other important functions that may have tumour suppressor effects (for review, see [9]).

Many nonrenal cancers are also characterised by hypoxia, enhanced HIF levels and increased expression of hypoxically regulated genes which correlate both with tumour aggression and patient outcome [4]. Recently, comprehensive gene arrays have emphasised the dominant role of the HIF-VHL transcriptional system and the HIF peptidyl hydroxylases in the regulation of gene expression by hypoxia [7] and have characterised HIF-dependent and HIF-independent pathways of transcriptional regulation in VHL-deficient cells. However, other mechanisms of gene regulation by hypoxia include control of mRNA stability, regulation of mRNA translation, global influences on the transcriptional machinery and regulation mediated by microRNAs (miRNAs) [10].

miRNAs are noncoding RNA oligonucleotides that function as important regulators of gene expression. Differential levels of specific miRNAs have been observed in several tumour types when compared to normal tissue $[11,12]$. In addition, global reductions in miRNA expression are a feature of many cancers, miRNA gene copy number variation appears common in cancer, and overexpression of miRNAs can contribute to oncogenesis [13-15]. mRNA targets of these miRNAs include genes encoding proteins with roles in apoptosis, cell cycle and growth (for review, see [16]). Furthermore, certain tumour suppressors such as p53 can directly influence miRNA production [17], and gene polymorphisms of components of the miRNA biogenesis machinery have been associated with renal cell carcinoma susceptibility [18]. The precise mechanisms underlying inducible production of miRNAs, the role of tumour suppressors, such as VHL, in miRNA regulation and the effects of the HIF-VHL system on miRNA activity require further definition, as does the contribution of VHL-dependent alterations in miRNA abundance to the pathogenesis of renal cancers.

To determine the possible role of miRNAs in hypoxic gene regulation and to examine for hypoxically regulated miRNAs that may have relevance to tumour pathogenesis, we have surveyed changes in miRNA expression levels in response of breast cancer cells to hypoxia and characterised the hypoxic regulation of one specific human miRNA (miR-210) [19,20]. Given the link between hypoxia and miR-210 regulation and the recognition of particular alterations in miRNA expression in cancer, we hypothesised that levels of miR-210 expression in cancer would correlate with degree of hypoxia and tumour behaviour. To test this hypothesis, we have recently examined the expression of this hypoxically induced miRNA in human breast cancers and found a striking association with breast cancer prognosis $[19,20]$. Given the central role of VHL in hypoxic gene regulation and in renal cancer formation, we wished to examine the VHL-dependent regulation of miRNAs in renal cancer. miRNA dysregulation has been observed in renal cancer, and miR-210 has been identified as a hypoxia and VHL-regulated miRNA in renal cancer cells [21-23]. We wished to understand the mechanism underlying such alterations, examine the extent to which VHL-mediated alterations in miRNAs were HIF-dependent or independent and examine for the utility of miRNA alterations in renal cancer diagnosis.

\section{Methods \\ Cell lines}

The renal cancer cell line RCC4 stably transfected with either an empty vector or a vector encoding VHL was used in this study [24]. Cells were grown in Dulbecco's modified Eagle's medium supplemented with $10 \%$ fetal bovine serum (Invitrogen, Newcastle, NSW, Australia). All experiments were conducted in triplicate with independent cell cultures.

\section{Cell treatments}

Treatment of cells with dimethyloxalylglycine (DMOG) (Biomol International, Plymouth Meeting, PA, USA) involved supplementing cell media with $1 \mathrm{mM}$ DMOG diluted in phosphate-buffered saline (PBS) for 24 hours $[25,26]$.

For HIF- $1 \alpha$ and HIF- $2 \alpha$ small interfering RNA (siRNA) treatments, RCC4-VHL cells were seeded at 30$50 \%$ confluency and grown for 24 hours. Cells were then transfected with $50 \mathrm{mM}$ HIF-1 $\alpha$ (sense 5'-CUGAUGAC CAGCAACUUGAdTdT-3' and antisense 5'-UCAAGUU GCUGGUCAUCAGdTdT-3'; Dharmacon, Lafayette, CO, USA), HIF- $2 \alpha$ siRNA (sense 5'-CAGCAUCUUU GAUAGCAGUdTdT-3' and antisense 5'-ACUGCUAU CAAAGAUGCUGdTdT-3'; Dharmacon) [19] and Accell negative control kit (Dharmacon) using Lipofectamine 2000 (Invitrogen). After 48 hours, RNA and protein were extracted.

For miR-210 overexpression studies, $20 \mathrm{nM}$ miR-210 oligonucleotide duplex (sense 5'-CUGUGCGUGUGA CAGCGGCUGA-3' and antisense 5'-AGCCGCUGUCA CACGCACAGUU-3'; GenePharma, Shanghai, China) and $20 \mathrm{nM}$ mimic negative control (sense 5'-UUCUCC 
GAACGUGUCACGUTT-3' and antisense 5'-ACGUGA CACGUUCGGAGAATT-3'; GenePharma) were transfected into RCC4 + VHL cells seeded at $30-50 \%$ confluency. RNA was harvested after 48 hours.

For miR-210 repression studies, $20 \mathrm{nM}$ miR-210 siRNA (5'-UCAGCCGCUGUCACACGCACAG-3'; GenePharma) and $20 \mathrm{nM}$ miRNA inhibitor negative control (5'-UCUACUCUUUCUAGGUUGUGA-3'; GenePharma) were transfected into RCC4-VHL cells seeded at 30-50\% confluency. RNA was harvested after 48 hours.

\section{Microarray}

The miRNA microarrays consisted of 1488 antisense miRNA oligonucleotide probes (miRCURY LNA microRNA probe set, catalog no. 208010 V8.1; Exiqon, Vadbaek, Denmark) printed in duplicate onto epoxidecoated microarray slides (Corning Life Sciences, Acton, MA, USA). For detection on the array, $5 \mu \mathrm{g}$ of total RNA was labelled by the ligation of a fluorescently modified RNA dimer [27]. Two sample (dual colour) competitive hybridizations were performed using Cy3- and Cy5-labelled sample pairs.

Hybridisation was performed for 16 hours at $56^{\circ} \mathrm{C}$ under LifterSlips (Erie Scientific, Portsmouth, NH, USA) in $1 \times$ Exiqon hybridization buffer (catalog no. 208020) (Exiqon, Vadbaek, Denmark) in a total volume of $25 \mu \mathrm{L}$.

Slides were placed in Corning hybridization chambers and protected from light for the 16-hour incubation. Slides were washed using dilutions of the Exiqon Wash Buffer kit (catalog no. 208021) as recommended by the manufacturer. Slides were scanned at $10-\mu \mathrm{m}$ resolution with a Genepix 4000B Scanner (Molecular Devices, Union City, CA, USA).

Median spot pixel intensity values in scanned images were extracted using the Spot v3 plugin (CSIRO, Clayton South, VIC, Australia) for the statistical environment R. After subtraction of background intensities and global loess normalisation, mean intensities were $\log _{2}$ transformed and ratios (Cy5/Cy3) were obtained. Differentially expressed miRNAs were determined using linear models and empirical Bayesian moderation of standard errors (LIMMA R package, WEHI, Melbourne, VIC, Australia; [28]).

\section{Immunoblotting}

Whole cell extracts were resolved by standard polyacrylamide gel electrophoresis and electroblotted onto polyvinylidene difluoride membrane (Millipore, Bedford, MA, USA). Primary antibodies used were mouse monoclonal anti-HIF-1 $\alpha$ (610958; BD Transduction Laboratories, San Diego, CA, USA) and rabbit polyclonal antiHIF-2 $\alpha$ (NB100-122; Novus Biologicals, Littleton, CO, USA). Horseradish peroxidase-conjugated secondary antibodies goat anti-rabbit IgG and donkey anti-mouse
IgG (Immunopure; Thermo Scientific, Rockford, IL, USA) were used in conjunction with the ECL system (SuperSignal West Pico; Pierce, Rockford, IL, USA) to visualise bands using an ImageQuant LAS 4000 system (GE Healthcare Life Sciences, Uppsala, Sweden).

\section{Patient samples}

Thirty-one patients with cc RCC treated in Adelaide, South Australia, Australia, between 1997 and 2006 were studied. Samples were obtained from the Flinders Medical Centre/Repatriation General Hospital Tissue Bank facility. Ethical approval for analysis of samples was obtained from the Flinders Clinical Research Ethics Committee (FCREC). All patients gave informed, signed consent. The clinical details of the patients are summarised in Table 1.

Quantitative real-time PCR for miRNAs, CAIX and ISCU1/2 miRNA expression was assessed by relative quantitation real-time PCR (qPCR) using TaqMan microRNA assays (Applied Biosystems, Foster City, CA, USA).RNA was

\section{Table 1 Summary of the clinical characteristics of 31} patients with CC RCC

\begin{tabular}{|c|c|}
\hline Clinical Features & Number of patients \\
\hline \multicolumn{2}{|l|}{ Sex } \\
\hline Female & 6 \\
\hline Male & 25 \\
\hline \multicolumn{2}{|l|}{ Age (yr) } \\
\hline Median & 67 \\
\hline Range & $31-88$ \\
\hline \multicolumn{2}{|l|}{ Grade } \\
\hline 1 & 3 \\
\hline 2 & 16 \\
\hline 3 & 10 \\
\hline 4 & 2 \\
\hline \multicolumn{2}{|l|}{ TMN Stage } \\
\hline pT1 & 5 \\
\hline pT2 & 6 \\
\hline рТ3а & 8 \\
\hline pT3b & 2 \\
\hline pT4 & 1 \\
\hline Unknown & 9 \\
\hline \multicolumn{2}{|l|}{ Size $(m m)$} \\
\hline $21-50$ & 18 \\
\hline $51-100$ & 7 \\
\hline $101-150$ & 4 \\
\hline $151-200$ & 0 \\
\hline $201-250$ & 1 \\
\hline Unknown & 1 \\
\hline
\end{tabular}

Pathological details of cc RCC tumours according to Fuhrman's grading system and the International Union Against Cancer (UICC) TNM classification. The size of tumours (in $\mathrm{mm}$ ) and the age and gender of the 31 patients is also shown. 
extracted from cells and tissue using TRIzol reagent (Invitrogen) according to the manufacturer's instructions. RNA quantity and quality was determined using a Nanodrop-8000 spectrophotometer (Nanodrop Technologies, Wilmington, DE, USA). cDNA was synthesised from $5 \mathrm{ng}$ of total RNA using TaqMan miRNA-specific primers and the TaqMan microRNA reverse transcription kit (Applied Biosystems). qPCR was performed using the Corbett Rotor-gene 2000. Each PCR was performed in triplicate and contained $1 \mu \mathrm{l}$ of reverse transcription product, $1 \times$ TaqMan Universal PCR Master Mix No AmpErase UNG and $0.5 \mu \mathrm{l}$ of primer and hydrolysis probe mix of the TaqMan microRNA assay (assay IDs: miR-210: 000512, miR-155: 000479, miR-21: 000397, miR-31: 001100, miR-20a: 000580, miR-18a: 002422, miR-17: 000393, let-7i: 002221, miR-193b: 001010; Applied Biosystems). The 10- $\mu$ l reactions were incubated at $95^{\circ} \mathrm{C}$ for 10 minutes, followed by 40 cycles of $95^{\circ} \mathrm{C}$ for 15 seconds and $60^{\circ} \mathrm{C}$ for 60 seconds. Results were normalised to the expression of the small nuclear RNA gene RNU6B (assay ID: 001093; Applied Biosystems) for cell samples and an average of the small nucleolar RNAs RNU43 and RNU48 (assay IDs: 001095 and 001006, respectively; Applied Biosystems) expression levels for tissue samples, as no significant variation of expression was found between tumour and normal tissue. Data were generated and analysed using Corbett Rotorgene software (version 5.0.61) (Corbett Research, Sydney, NSW, Australia) and the Relative Expression Software Tool (REST) program (Corbett Research, Sydney, NSW, Australia) [29].

For mRNA expression studies, $1 \mu \mathrm{g}$ of RNA was reverse transcribed following DNase treatment (New England Biolabs, Beverly, MA, USA) using M-MLV Reverse Transcriptase RNase H minus, Point mutant (Promega, Madison, WI, USA) and Oligo dT(15) primers. Carbonic anhydrase IX (CAIX) mRNA expression was assessed by qPCR according to the SYBR Green protocol (Applied Biosystems). The following primers were used to amplify CAIX (each at $0.25 \mu \mathrm{M}$ per reaction): forward $5^{\prime}-\mathrm{CC}$ TCTCCCGGAACTGAGCCTAT-3' and reverse 5'-TG TTCTGAGCCTGGGTGATCTG-3' [30]. Iron-sulfur cluster assembly (ISCU1/2) mRNA expression was assessed by $\mathrm{qPCR}$ using the ISCU1/2 TaqMan gene expression kit (assay ID: Hs00384510_m1; Applied Biosystems) according to the manufacturer's instructions, and the human $\beta$-actin gene was used as a reference using the following primers (each at $0.25 \mu \mathrm{M}$ per reaction): forward 5'-TTGCCGACAGGATGCAGAAG-3' and reverse 5'-GCCGATCCACACGGAGTACT-3'.

\section{VHL sequencing}

Mutation analysis of the promoter region, three exons and associated splice junctions of the VHL gene were performed by PCR amplification and cycle sequencing. Genomic DNA was extracted from tumour samples using the DNeasy kit, spin-column protocol (Qiagen, Hilden, Germany) according to the manufacturer's instructions. DNA was PCR amplified in 50- $\mu$ l reactions using AmpliTaqGold (Roche, Branchburg, NJ, USA) according to the manufacturer's instructions and the following conditions and primers. Promoter and Exon 1: Primers forward 5'-TAGCCTCGCCTCCGTTACA-3' and reverse 5'-GCTTCAGACCGTGCTATCG-3', Exon 2: Primers forward 5'-TGATCTCCTGACCTCATGAT-3' and reverse 5'- GACACCATAACACCTTTA AC-3' and Exon 3: Primers forward 5'-TACTGA GACCCTAGTCTG-3' and reverse 5'-GGAAGGAAC CAGTCCTG-3'. PCR primers for exons 1 and 3 were tagged with universal M13 primers. PCR products were visualised on agarose gel and purified using ExoSAP-IT (GE Life Sciences) according to the manufacturer's instructions. Cycle sequencing was performed using universal M13 forward and reverse primers for exons 1 and 3 and the PCR primers for exon 2 and standard BigDye (Applied Biosystems) chemistry. Sequencing products were purified using Agencourt CleanSEQ Dye Terminator Removal (Beckman Coulter, Beverley, MA, USA) according to the manufacturer's instructions and analysed on an Applied Biosystems 3730 analyser.

Sequence traces were compared to the National Center for Biotechnology Information (NCBI) reference sequence NM_000551.2 using Mutation Surveyor (SoftGenetics, State College, PA, USA). Splice site variants were analysed using the Berkeley Drosophila Genome Project (BDGP) http://www.fruitfly.org/about/index. html, NetGene2 http://www.cbs.dtu.dk/services/NetGene2/ and GeneSplicer http://www.cbcb.umd.edu/software/GeneSplicer/gene_spl.shtml splice site predictors. Human Genome Variation Society (HGVS) nomenclature was used for variant identification [31].

\section{VHL promoter methylation analysis}

Bisulphite treatment followed by methylation-specific PCR (MSP) was used to analyse the methylation status of the VHL promoter [32]. Genomic DNA was subjected to bisulphite treatment using an EpiTect Bisulfite kit (Qiagen, Hilden, Germany) according to the manufacturer's instructions. The following primers were used for amplifying the VHL promoter: Unmethylated-specific (expected size $165 \mathrm{bp}$ ) forward 5'-GTTGGAGGA TTTTTTTGTGTATGT-3', reverse 5'-CCCAAACCA AACACCACAAA-3', and methylated-specific (expected size $158 \mathrm{bp}$ ) forward 5'-TGGAGGATTTTTTTGCG TACGC-3', reverse 5'-GAACCGAACGCCGCGAA-3' [33]. The PCR mixture contained $1 \times$ PCR buffer (New England Biolabs), deoxynucleotide triphosphates (each at $2.5 \mathrm{mM}$ ), primers (each at $0.8 \mathrm{mM}$ ), $50 \mathrm{ng}$ modified 
DNA and 2.5 U of Taq DNA polymerase (New England Biolabs) added after a 5 -minute at $95^{\circ} \mathrm{C}$ hot start, in a total reaction volume of $50 \mu \mathrm{l}$. Reactions were carried out on a GeneAmp PCR system 9700 thermocycler (Applied Biosystems) for 35 cycles $\left(30\right.$ seconds at $95^{\circ} \mathrm{C}$, 30 seconds at $47^{\circ} \mathrm{C}$ and 30 seconds at $72^{\circ} \mathrm{C}$ ), followed by a final extension of 4 minutes at $72^{\circ} \mathrm{C}$. Each PCR was loaded $(20 \mu \mathrm{l})$ onto a $3 \%$ agarose gel containing ethidium bromide and visualised under UV light.

\section{Statistical analysis}

All statistical analysis was done using PASW Statistics 17 (Somers, NY, USA). The Mann-Whitney $U$ test was used to assess the difference between miRNA expression in RCC4 \pm VHL cells, treated/untreated cells and tumour/normal adjacent tissue. Spearman's $\rho$ correlation coefficient was used to assess correlations between miRNA expression and ISCU1/2 and CAIX expression and for the correlation of miR-210, miR-155, miR-21, miR-18a, let-7i, ISCU1/2 and CAIX expression with survival, tumour size, grade and tumour node metastasis (TNM) stage. Kaplan-Meier log-rank (Mantel-Cox) analysis was undertaken to assess overall survival, miR-210 expression and TNM stage. Results were considered statistically significant at $P \leq 0.05$.

\section{Results and Discussion}

\section{VHL regulation of miRNA expression in RCC4 cells}

To test the hypothesis that there are specific alterations in miRNA expression in VHL-dependent renal cancer, we studied parallel cultures of renal carcinoma cells with mutated VHL (RCC4-VHL) and reintroduced wildtype VHL (RCC4 + VHL). We analysed these cells for expression of both HIF- $1 \alpha$ and HIF- $2 \alpha$ and, in keeping with previous studies [24], confirmed high levels of HIF in cells lacking functional VHL (Additional file 1). We undertook a microarray analysis of miRNA expression in RCC4 cells and compared expression in cells with and without functional VHL (Figure 1).

Whilst the majority of miRNAs showed no substantial difference in expression, some showed very significant VHL-dependent differences. miRNAs with a positive Bayesian log odds value were considered to be differentially expressed (Figure 1). Furthermore, we sought to confirm these findings by measuring the expression of the top five up- and downregulated human miRNAs in RCC4-VHL by qPCR in independent experiments, in addition to miR-210, which we had previously shown to be regulated by the HIF-VHL system [34]. Of the selected downregulated miRNAs, miR-21, miR-31 and let-7i were found to be slightly repressed 1.9-, 1.7- and 1.4-fold, respectively; $P=0.05$ (RCC4-VHL compared to RCC4 + VHL) (Figure 2a). No TaqMan assay is currently available to validate miR-663 expression by qPCR, and the downregulation of miR-720 was not detectable in our assays. All of the selected upregulated miRNAs, miR-155, miR-193b, miR-18a, miR-20a and miR-17 (also known as miR-17-5p), were found to be highly expressed in cells without functional VHL (13.0-, 5.2-, 3.8-, 3.1- and 2.3-fold, respectively; $P=0.05$ ) (RCC4VHL compared to RCC4 + VHL) (Figure 2b). Consistent with other reports [35], the amplitude of differential expression was higher than had been assessed with the microarray platform. Furthermore, the differential expression of miR-210 was confirmed (16-fold; $P=0.05$ ) (RCC4-VHL compared to RCC4 + VHL) (Figure 2b). The results were controlled and normalised by reference to expression of RNU6B, whose levels we have previously shown to be unaffected by VHL status and hypoxia [34].

Although the microarray analysis may not have detected the expression of all VHL-regulated miRNAs, the subsequent qPCR validation confirms the existence of substantial VHL-dependent regulation of multiple specific miRNAs in cell culture. The VHL-dependent miRNA expression pattern we observed might be mediated by enhanced levels of HIF- $\alpha$ proteins or alternatively might be due to other effects of VHL. HIF-independent functions of VHL have been described in cellular senescence, microtubule stability and matrix formation [9]. To examine the extent to which this pattern of VHL-dependent miRNA dysregulation was mediated by the HIF system, we examined the effects of the prolyl hydroxylase inhibitor DMOG, which activates HIF and a HIF-dependent pattern of gene expression $[7,26]$. We confirmed this induction of HIF- $1 \alpha$ and HIF- $2 \alpha$ by DMOG in the RCC4 + VHL cells (Additional file 1) and also confirmed the induction of the HIF target, CAIX, by DMOG in the RCC4 + VHL cells (Additional file 2). Of the five miRNAs confirmed to be upregulated in RCC4-VHL cells, only miR-155 and miR-193b were found to be slightly upregulated in response to DMOG treatment in RCC4 + VHL (1.6- and 1.5-fold, respectively; $P=0.05$ ) (Figure $3 \mathrm{~b}$ ), although the amplitude of induction was less than that seen between cells differing in VHL status. Figure 3a shows that the three miRNAs (miR-31, miR-21 and let-7i) confirmed to be downregulated in the RCC4-VHL cell line are not downregulated in response to DMOG treatment of the RCC4 + VHL cell line. As expected, the expression of miR-210 also increased with DMOG treatment (15-fold; $P=0.05$ ) (Figure 3b).

To further explore whether the miRNAs induced in the absence of VHL are indeed regulated by HIF, we transfected the RCC4-VHL cell line with HIF- $1 \alpha$ and HIF- $2 \alpha$ siRNA oligonucleotides. Figure 4 shows that following treatment to suppress HIF expression, the levels of miR210 and miR-155 were decreased in the treated lines 


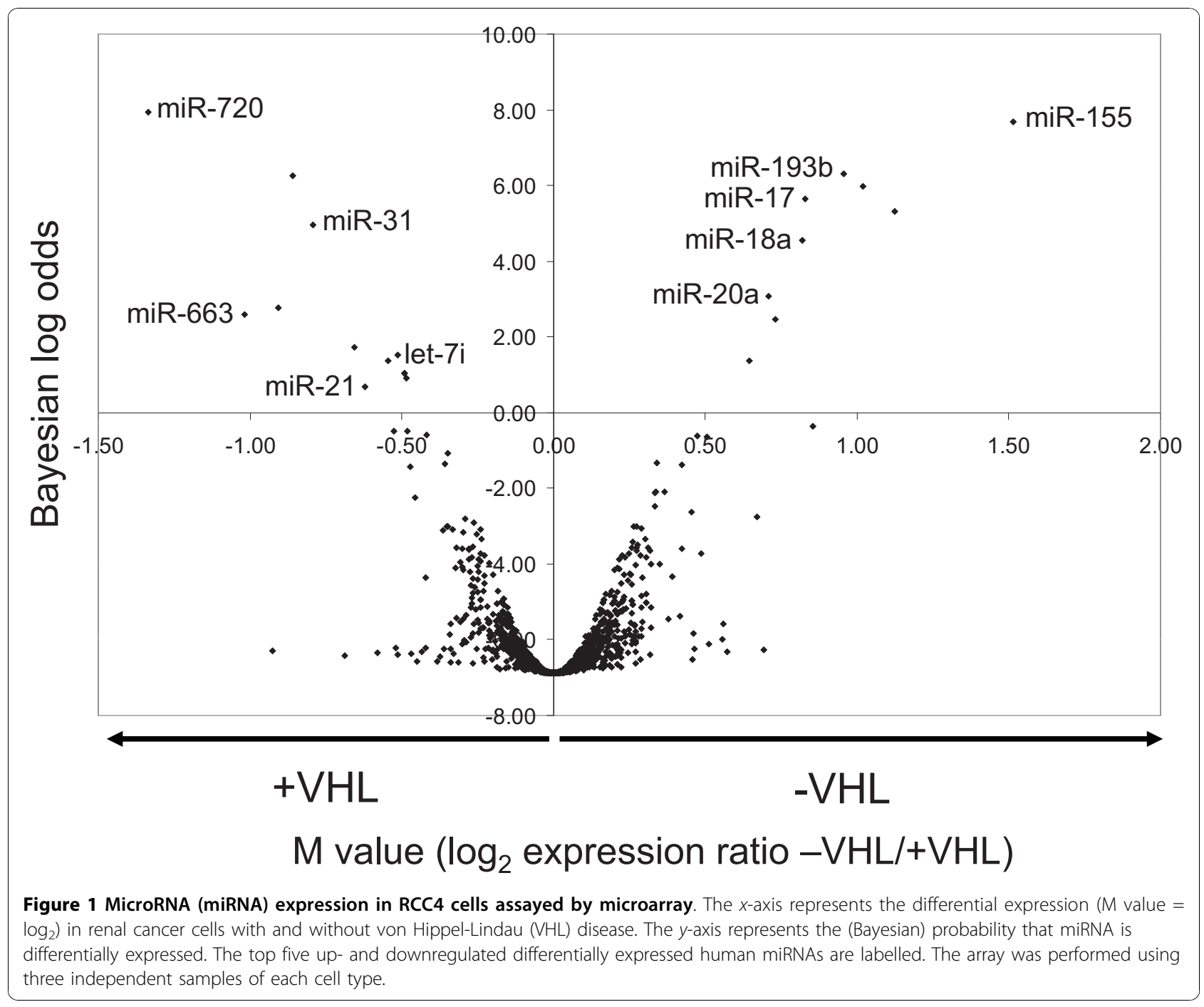

compared to those treated with a negative transfection control. HIF-1 $\alpha$ siRNA treatment decreased miR-210 and miR-155 levels 1.75- and 2.8-fold, respectively, and HIF- $2 \alpha$ siRNA treatment decreased miR-210 and miR155 levels 1.6 - and 2.8 -fold, respectively $(P=0.05)$, in keeping with the results of HIF hydroxylase inhibition and consistent with a role for HIF in their control. However, miR-193b did not show any change between treated and control cells, which may indicate that miR$193 \mathrm{~b}$ regulation is only partially mediated by HIF. Furthermore the lesser effect on miRNA regulation seen with HIF repression compared to that seen with DMOG treatment may represent insufficient duration of HIF repression or incomplete transfection efficiency in these cells. Taken together, these results suggest that the induction of several miRNAs in cells lacking VHL is mediated in large part via HIF induction (miR-210 and miR-155), whilst the dysregulation of other miRNAs
(miR-31/miR-21/miR-18a/miR-17/let-7i/miR-20a) is HIF-independent and mediated by other actions of VHL.

\section{Analysis of VHL-dependent miRNA expression in renal tumours}

Given these interesting observations in one particular renal cancer cell line, we examined whether this signature of VHL-dependent miRNA dysregulation occurs in renal tumours. This would provide information about the extent to which these specific VHL-dependent miRNA alterations are more widely observed in renal cancer, with important implications for understanding renal oncogenesis and developing diagnostic and prognostic markers in renal cancer.

To address the hypothesis that VHL-regulated miRNAs are also dysregulated in renal tumours, we examined the nine miRNAs found to be differentially expressed between RCC4-VHL and RCC4 + VHL cell 

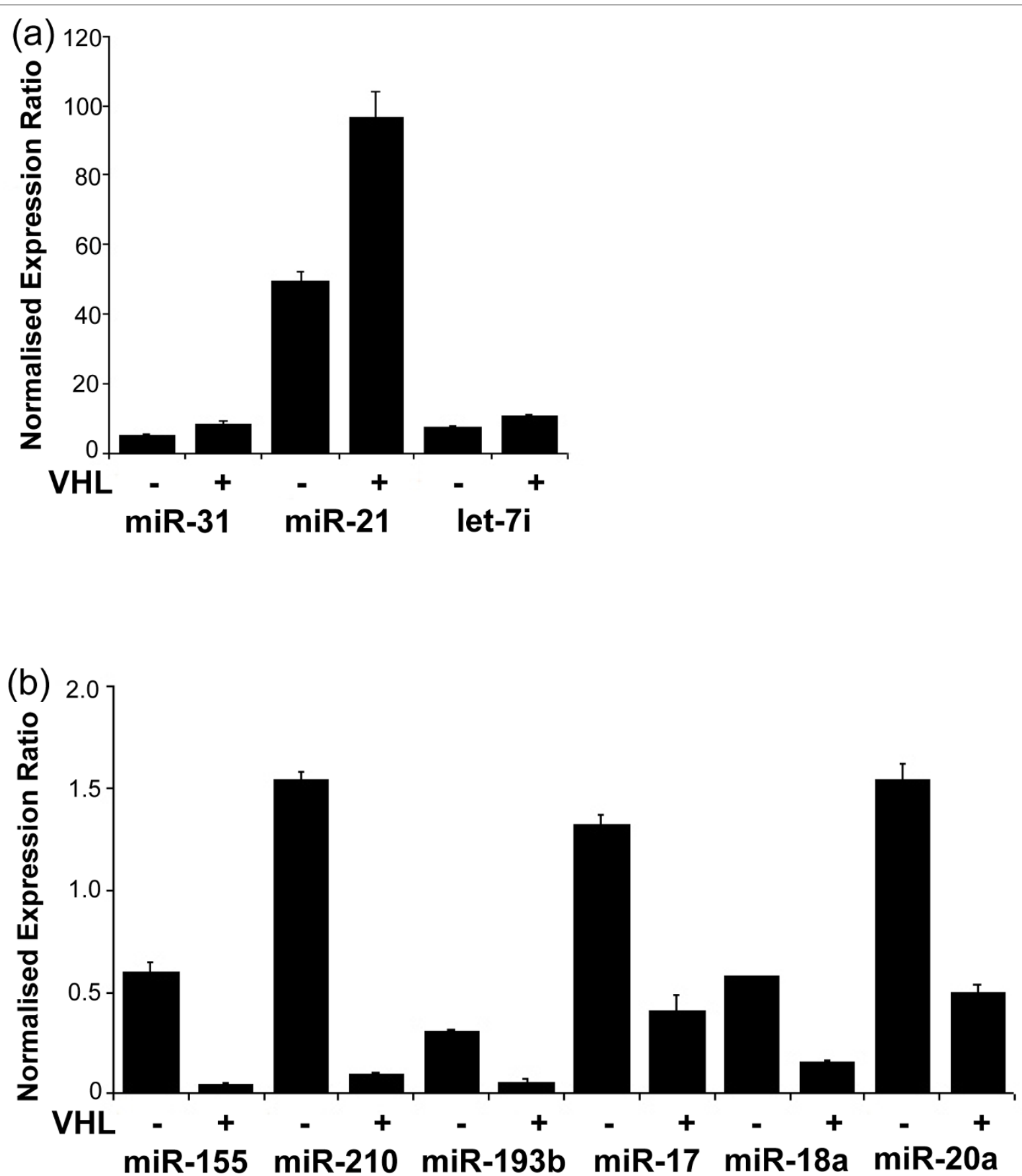

Figure $\mathbf{2}$ VHL regulation of miRNA expression in RCC4 cells. Expression of VHL-regulated miRNAs was validated by relative quantitation realtime PCR (qPCR). (a) VHL-dependent downregulation of miR-31, miR-21 and let-7i in RCC4-VHL cells $(P=0.05)$. (b) VHL-dependent upregulation of miR-155, miR-210, miR-193b, miR-17, miR-18a and miR-20a in RCC4-VHL $(P=0.05)$. The expression of the miRNAs was normalised to RNU6B expression. The mean \pm SEM of three independent cell cultures is shown, and each sample was assayed in triplicate.

lines. The expression of several of these miRNAs was found to be upregulated in 31 cc RCC tumours compared to adjacent normal tissue (Figure 5). The expression of each miRNA was normalised to an average of RNU43 and RNU48 expression, both of which were found not to be differentially expressed between tumour and normal tissue $(0.96$-fold $(P=0.906)$ and 1.02 -fold $(P=0.746)$ expression in tumour relative to adjacent normal tissue, respectively). Figure 5 a shows the expression of miR-210, miR-155 and miR-21, which are 


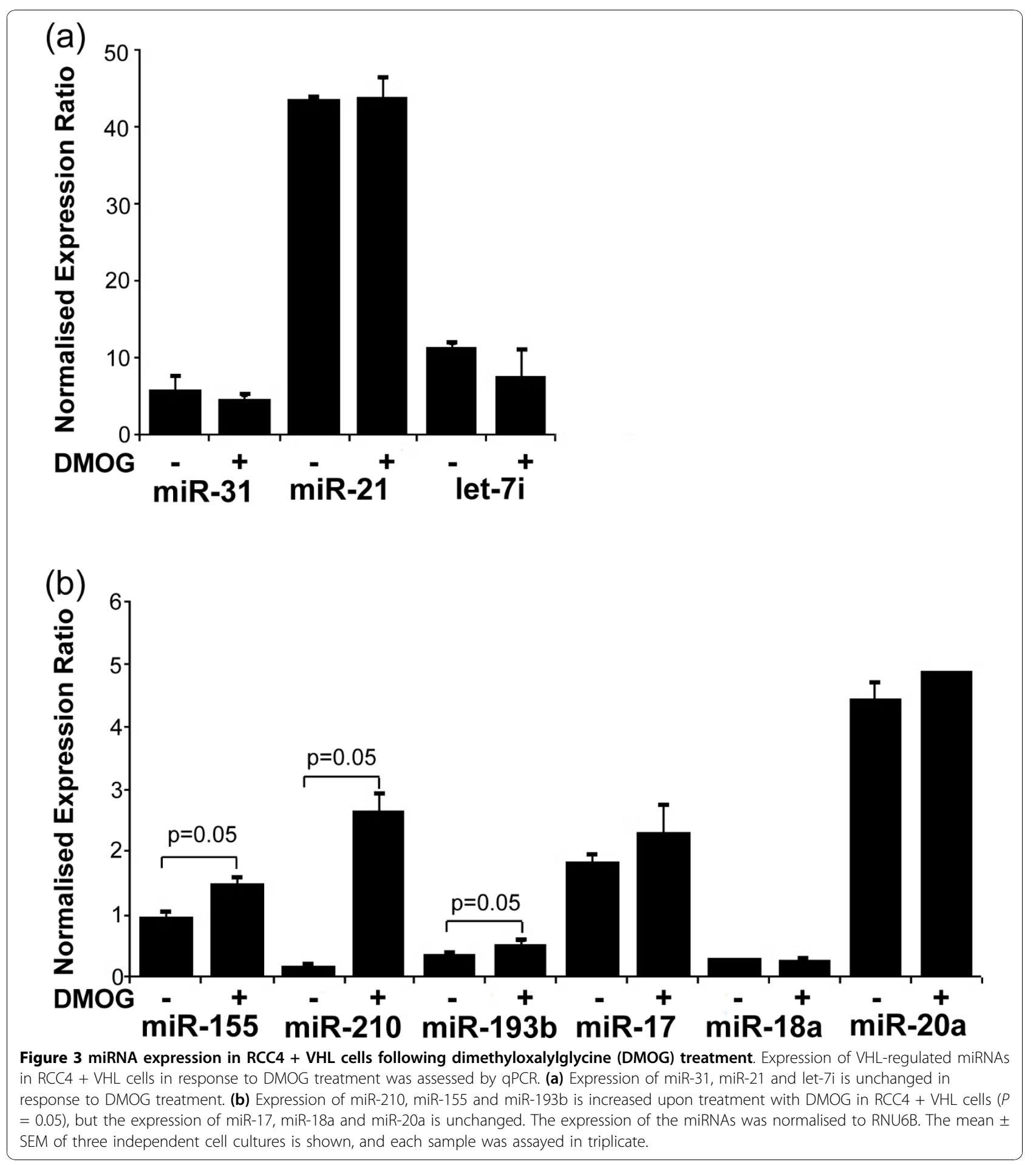

significantly upregulated in tumour tissue compared to normal adjacent tissue (8-, 16- and 4-fold, respectively; $P \leq 0.0001)$. The expression of three members of the miR-17-92 cluster in tumour tissue was also examined. miR-18a was upregulated in clear cell tumour tissue compared to adjacent normal tissue (1.6-fold; $P \leq$
0.0001), however, while miR-20a also appeared to be slightly upregulated (1.3-fold), this was not statistically significant $(P=0.067)$. The expression of miR-17 was not found to be significantly different in tumour compared to normal adjacent tissue (Figure 5b). The miRNAs miR-193b and miR-31 were not significantly 


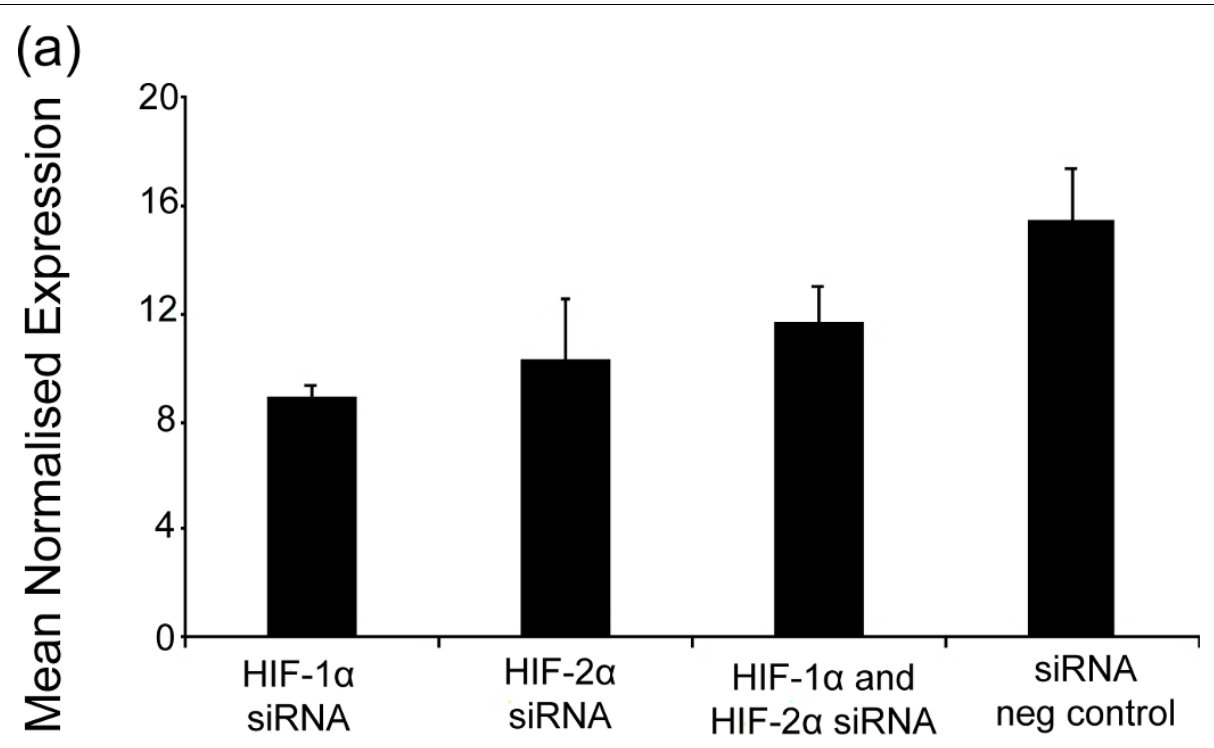

(b)

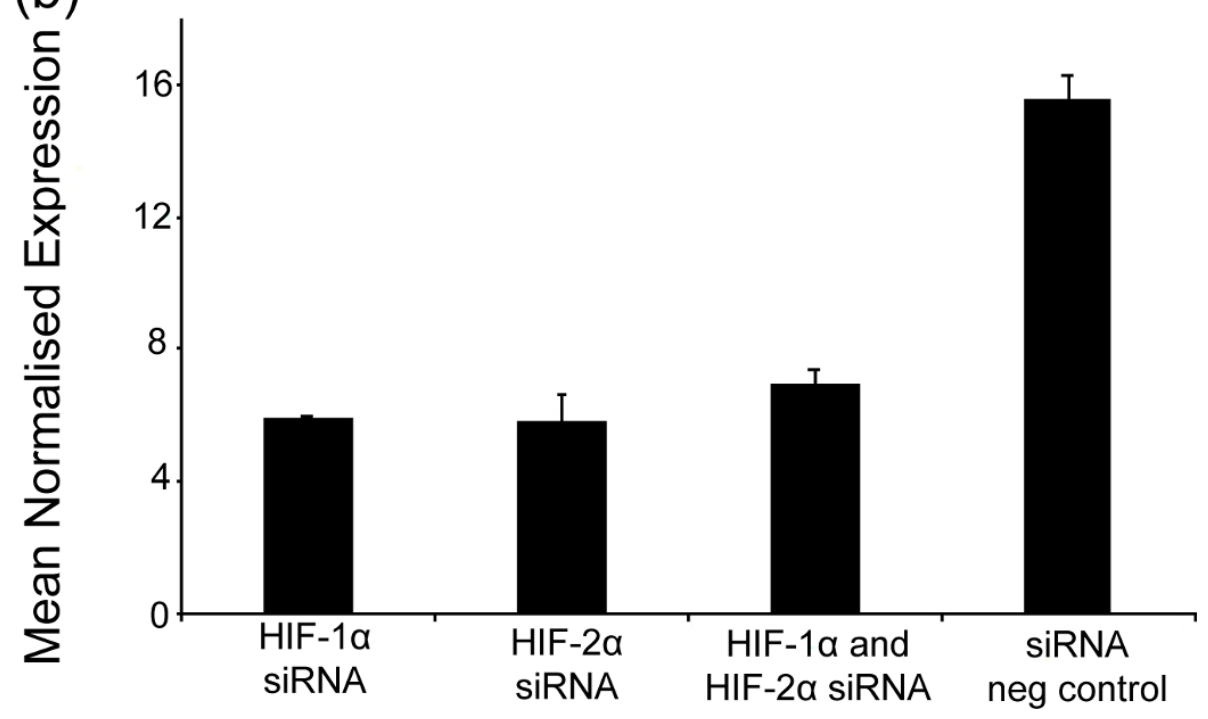

Figure 4 miRNA expression in RCC4-VHL cells following hypoxia-inducible factor (HIF) small interfering RNA (siRNA) treatment Expression of VHL-regulated miRNAs in RCC4-VHL cells in response to HIF- $1 \alpha$ and HIF-2 $\alpha$ siRNA treatment was assessed by qPCR. (a) Expression of miR-210 is decreased in response to HIF siRNA treatment in RCC4-VHL cells $(P=0.05)$. (b) Expression of miR-155 is also decreased upon treatment with HIF siRNA in RCC4-VHL cells $(P=0.05)$. The expression of the miRNAs was normalised to RNU6B. The mean \pm SEM of three independent cell cultures is shown, and each sample was assayed in triplicate.

different between tumour and adjacent normal tissue; however, let-7i was slightly upregulated 1.2 -fold in tumour tissue $(P=0.043)$ (Figure $5 \mathrm{c})$. Of interest are four normal tissue samples in Figure 5a which are outliers and display miR-210 levels as high as the mean tumour expression level. It is possible that the normal kidney tissue taken from these patients was diseased or hypoxic as a consequence of the adjacent tumour, leading to abnormally high miR-210 expression levels.
These results show that some of the VHL-regulated miRNAs, such as miR-210 and miR-155 in cultured cells, are highly differentially expressed between renal cancer tissue and normal tissue. However, other miRNAs such as miR-31 and miR-193b do not show such regulation and indeed, somewhat surprisingly, miR-21 and let-7i, which were decreased in cells lacking VHL, were overexpressed in renal cancer when compared to normal adjacent renal tissue. This suggests that despite 

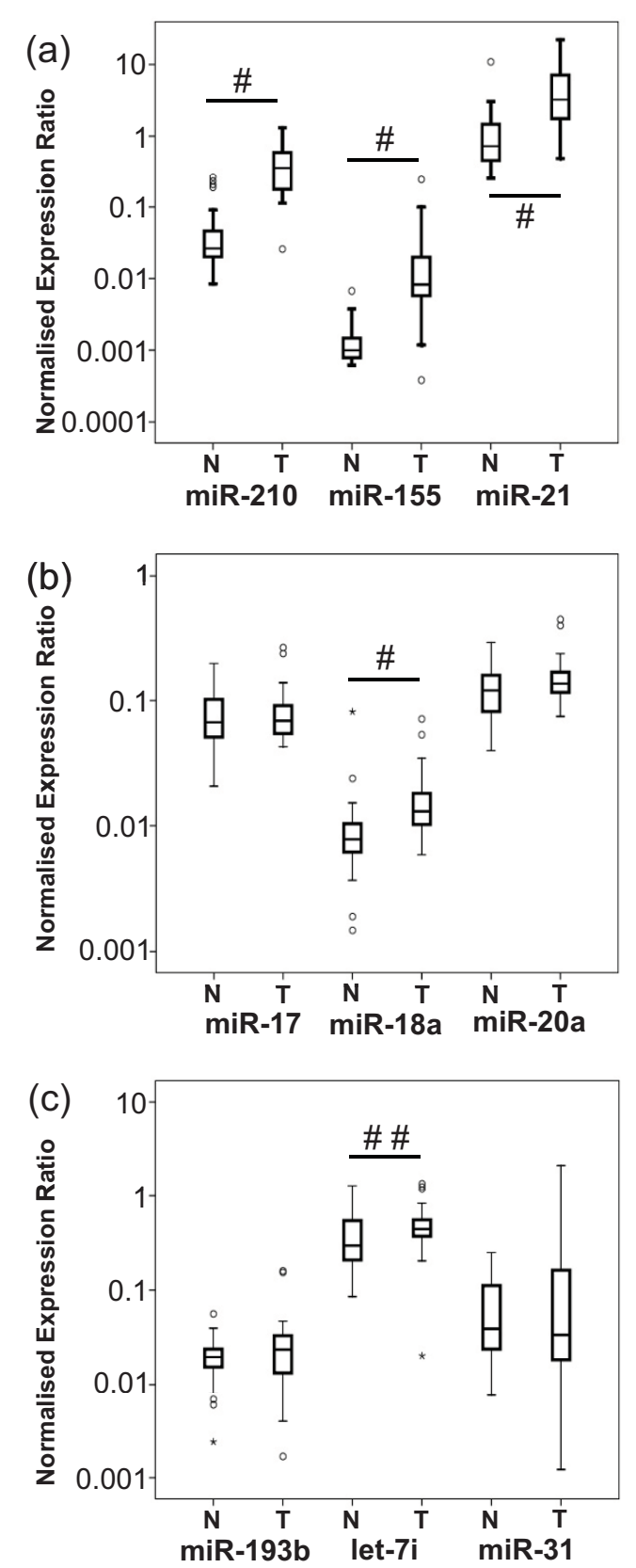

Figure 5 Expression of VHL-regulated miRNAs in clear cell renal cell carcinoma (cc RCC) tissue compared to normal adjacent tissue. Measurements of miRNA expression were determined by qPCR and normalised to an average of RNU43 and RNU48 expression. GPCR for each sample was performed in triplicate. (a) miR-210, miR-155 and miR-21 were all highly upregulated in tumour tissue compared to normal kidney tissue $(P$ $\leq 0.0001)$. (b) Expression of three members of the miR-17-92 cluster: miR-17, miR-18a and miR20a were examined, and miR-18a was found to be significantly upregulated in tumour tissue $(P \leq 0.0001)$ (c) No significant difference in expression was observed for miR193b and miR-31; however, let-7i displayed significant upregulation in tumour tissue $(P \leq 0.043)$. $\# P \leq 0.0001$; \#\#P $\leq 0.05$; outlier (values between 1.5 and 3 interquartile ranges (IQRs) from the end of box); *extreme outlier (values more than 3 IQRs from the end of box).
VHL regulation at the cellular level, tumour growth and progression select for enhanced miR-21 and let-7i expression in tumour cells or other cells within the renal cancers. The decrease in expression in RCC4-VHL cells may be an artefact of cell culture resulting from different selection pressures in culture compared to cc RCC tumour tissue. Also, there are many mechanisms that may lead to overexpression of miR-21 in renal cancer, and these may not be related to VHL function. The RCC4 cell line used in this study may not be representative of the situation in all renal cancers, and in future studies it would be beneficial to validate these findings in additional kidney cancer cell lines.

miR-21 has been identified as having oncogenic properties and is overexpressed in the majority of cancer types examined [36]. A host of tumour suppressor genes have now been validated as targets of miR-21 (for review, see [36]), and recently the suggestion has been made, on the basis of bioinformatics analysis, that VHL may be a target of miR-21 [22,37], but this awaits experimental validation. Our finding that miR-21 is upregulated in cc RCC tumours is in keeping with two recent studies profiling miRNA expression in renal cancer that have also identified miR-21 as upregulated in cc RCC tumour tissue compared to normal kidney tissue, although the increase in expression observed in our study (fourfold) was higher than previously reported (2.5- and 1.2-fold) [21,22].

The overexpression of miR-210 in cc RCC has also recently been reported [21-23]. miR-210 is also overexpressed in many other tumour types [16], most notably breast cancer, in which it was found to be a prognostic marker [19]. miR-155 is also overexpressed in many cancers [16] and has been shown to inhibit apoptosis by targeting tumour protein p53 inducible nuclear protein 1 (TP53INP1) [38]. In addition, O'Connell and others have found that inositol phosphatase SHIP1 is a target of miR-155 [39]. Our results are in accord with those of other studies which have found increased miR-155 expression levels in cc RCC tissue, although the reported fold increases (3.2- and 6.4-fold) [21,23] were less than what was found in this series (15-fold).

The differential expression of some members of the miR-17-92 cluster in cc RCC is particularly interesting, as overexpression of this miRNA cluster has been implicated in a wide range of cancers and has been shown to act as an oncogene [13-15]. miR-17-92 has been shown to play an important role in tumour cell proliferation and apoptosis $[16,40]$, to negatively regulate HIF- $1 \alpha$ expression [41] and appears to have a critical function in vascular endothelial growth factor-induced angiogenesis [42]. Under normal physiological conditions, miR17-92 is involved in the regulation of MYC-induced cell proliferation by inhibiting E2F1 expression; however, 
when miR-17-92 is overexpressed in many cancers, it can act with MYC to synergistically contribute to aggressive cancer development [14,43-45]. The overexpression of three members of the miR-17-92 cluster, miR-17, miR-20a and miR-18a, has previously been reported for cc RCC [21,37]. Our finding that these three miRNAs are upregulated in the RCC4-VHL cell line is in accord with findings in these studies; however, we were unable to confirm the upregulation of miR-17 in tumour tissue or the statistically significant upregulation of miR-20a. This discrepancy may be due to small sample size, differences in procedure or potential interference of other cell types in the tumour samples.

Eleven members of the let- 7 family have been identified in the human genome. The family was one of the earliest tumour suppressor miRNAs identified in cancer, and some members of the let-7 family can also have oncogenic roles [46]. The increased expression of one member of the let-7 family, let-7i, has been reported in breast cancer [47] and head and neck squamous cell carcinoma [48], and decreased expression is associated with chemotherapy resistance and shorter progressionfree survival in late-stage ovarian cancer patients [49]. To the best of our knowledge, this is the first report of a change in let-7i expression in renal cancer.

\section{The hypoxic and VHL status of the tumour tissue}

As some of the miRNAs display HIF-dependent regulation (Figure $3 \mathrm{~b}$ and Figure 4), we sought to examine HIF-dependent mRNA expression in the 31 tumour samples. CAIX is a transcriptional target of HIF-1. Its expression has previously been shown to be an intrinsic marker of hypoxia/HIF activation [50] and has been reported to be a predictor of outcome in renal cancer [51]. Thus, the expression level of CAIX in the cc RCC tumour tissue was determined to infer the presence of hypoxia and/or the likely activation of HIF. Consistent with this, an undetectable level of expression was observed in the normal matched adjacent tissue. Furthermore, a striking positive correlation was found between CAIX and miR-210 expression $(r=0.527, P=$ 0.002 ), as shown in Figure 6. No correlation was observed between CAIX levels and other VHL-regulated miRNAs, with the exception of miR-155 which showed a weak correlation $(r=0.318, P=0.082)$. This is consistent with the regulation of miR-155 by VHL through HIF-1 $\alpha$. These results provide additional support for the concept that several of the VHL-dependent miRNAs are at least partially regulated via HIF whilst others are regulated by HIF-independent mechanisms.

We also analysed miRNA and CAIX expression by whether the tumours had identifiable VHL defects. The tumours were analysed for VHL mutations and VHL promoter methylation status (Additional file 3). It has

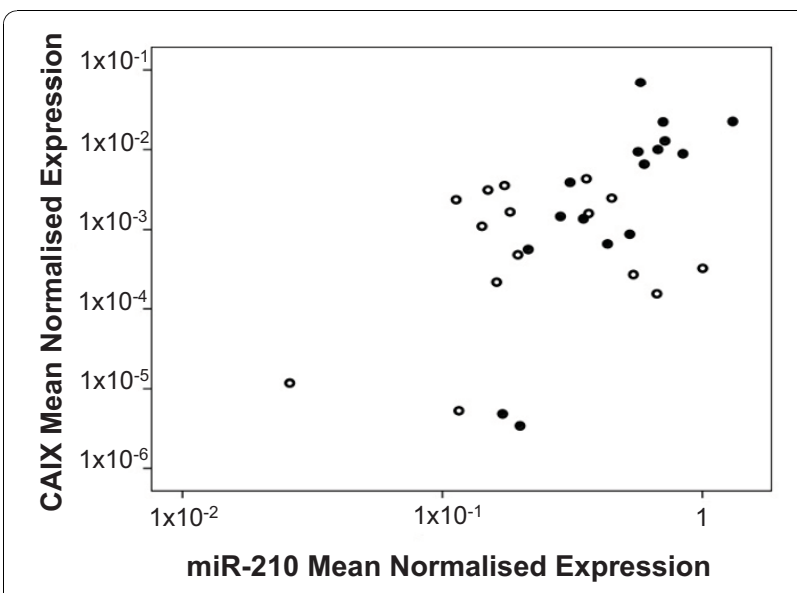

Figure 6 Correlation between carbonic anhydrase IX (CAIX) and miR-210 expression. Measurements of CAIX mRNA and miR-210 expression were determined by qPCR and normalised to $\beta$-actin mRNA expression and an average of RNU43 and RNU48 expression, respectively. QPCR for each sample was performed in triplicate. A significant positive correlation is observed between the mean normalised expression of CAIX and miR-210 ( $r=0.527, P=0.002)$. Data are displayed on $\log _{10}$ axes. Shaded circles indicate tumours which have VHL mutation and/or VHL promoter methylation, and open circles represent tumours for which no VHL defect has been identified.

been found that biallelic VHL mutations are found in $50-75 \%$ of sporadic cc RCC tumours [2,3]. In keeping with other series, VHL mutations were found in $42 \%$ of clear cell tumours [33], and the VHL promoter was found to be methylated in $10 \%$ of clear cell tumours $[52,53]$. We hypothesised that CAIX and HIF-regulated miRNAs would be indicative of the VHL status of the tumour, and indeed a significant difference between the two groups was observed for CAIX and miR-210 expression. CAIX and miR-210 expression were found to be significantly increased in tumours with identifiable VHL mutations, or promoter methylation, compared to tumours in which we did not identify a mechanism for suppression of VHL function $(P=0.045$ and 0.011 ; Figures $7 \mathrm{a}$ and $7 \mathrm{~b}$, respectively).

However, a substantial proportion of the tumours without identified VHL inactivation still display high expression of CAIX and miR-210. Whilst it is possible that our mutational and methylation analysis did not identify all of the causes of VHL inactivation present in these tumours, it indicates that they may have other genetic mutations that influence VHL or HIF expression or function. These mechanisms potentially include disruptions in SETD2 (histone H3K36 methyltransferase) or JARID1C (histone H3K4 demethylase), which have both been recently identified as having truncating mutations in approximately $3 \%$ of cc RCC tumours [54]. Other potential mechanisms of VHL suppression might be mediated via miRNAs, as has been reported recently for 

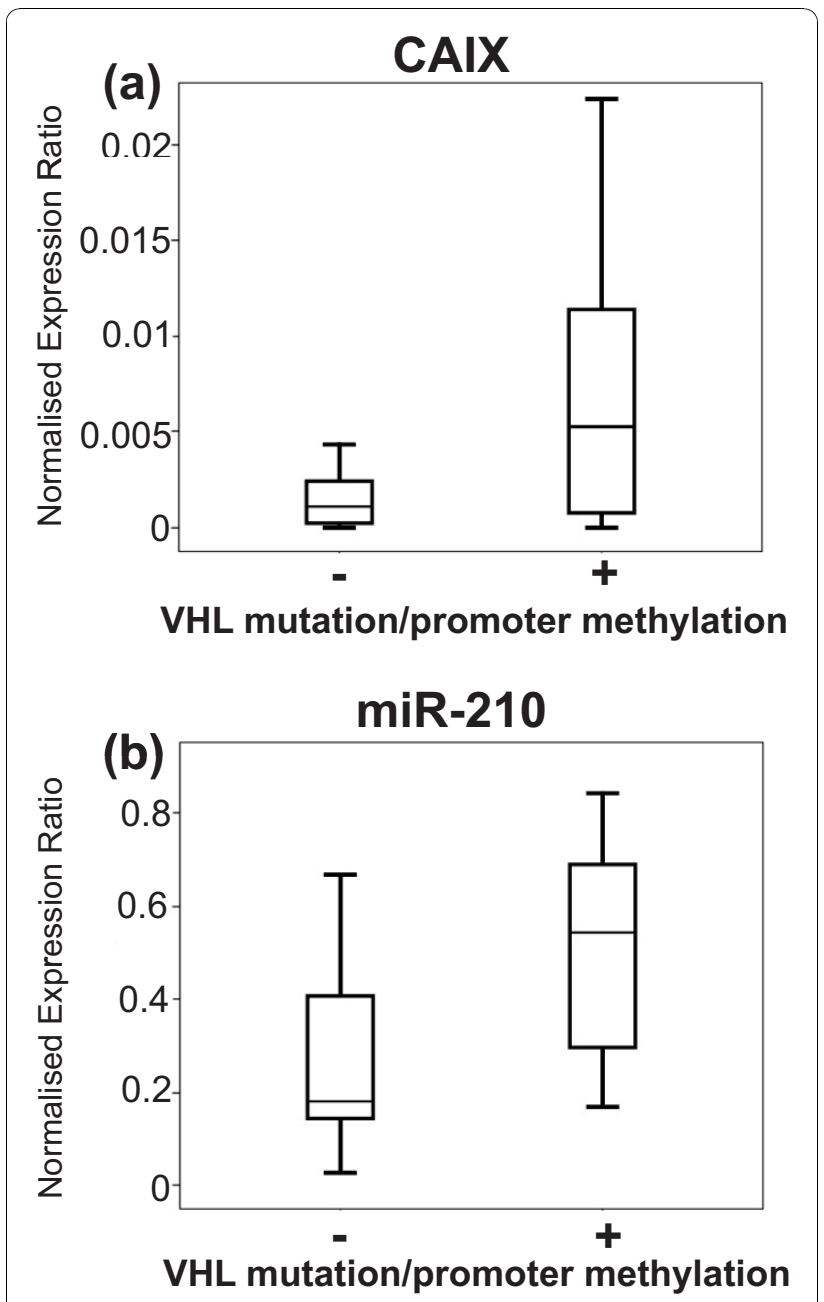

Figure 7 CAIX and miR-210 expression in tumours with and without VHL mutation and VHL promoter methylation. Measurements of CAIX mRNA and miR-210 expression were determined by qPCR and normalised to $\beta$-actin mRNA expression and an average of RNU43 and RNU48 expression, respectively. qPCR for each sample was performed in triplicate. Expression of CAIX and miR-210 was found to be increased in tumours with VHL mutation or promoter methylation compared to tumours in which neither was identified ( $P=0.045$ and 0.011 , respectively).

miR-92 in chronic lymphocytic leukaemia [55]. The mechanisms leading to cc RCC tumour initiation and/or activation of hypoxic pathways in tumours without VHL mutation or VHL promoter methylation are not well understood, and further work is needed.

\section{Correlation of miRNA level with clinical features}

Overall the 5-year survival in the $31 \mathrm{cc}$ RCC patients was $71 \%$. A significant inverse correlation was found between miR-210 expression in cc RCC tumours and survival (years) $(r=-0.481, P=0.006)$ (Figure $8 \mathrm{a})$. Weaker inverse correlations were also found between miR-21, let-7i and miR-18a expression in cc RCC tumour tissue and survival (years) $(r=-0.308, P=0.09 ; r=-0.339, P=0.062$; and $r=$ $-0.300, P=0.101$, respectively); however, the correlations did not achieve statistical significance. No correlation was found between miR-155 expression and survival (Figure $8 \mathrm{~b}$ ). The expected correlations between tumour size, grade, TNM stage and survival (years) were found $(r=$ -0.572, $P=0.001 ; r=-0.354, P=0.055$; and $r=-0.46, P=$ 0.031 , respectively).

A significant correlation was also found between miR155 and miR-21 expression in cc RCC tumours and tumour size $(\mathrm{mm})(r=0.408, P=0.028 ; r=0.434, P=$ 0.019 , respectively) shown in Figures $8 \mathrm{c}$ and $8 \mathrm{~d}$. Correlations were also observed for miR-210 and let-7i expression and tumour size $(\mathrm{mm})$; however, these correlations did not achieve statistical significance $(r=0.356, P=$ 0.058 ; and $r=0.363, P=0.053$, respectively). No correlations were found between miRNA expression in cc RCC tumours and tumour grade or TNM stage.

These results indicate the ability of levels of specific miRNAs to correlate with tumour features and patient outcome. The ability of levels of miR-210 to provide prognostic information has also been seen in breast cancer $[19,20]$ and head and neck cancers [56]. Figures 9a and $9 \mathrm{~b}$ show Kaplan-Meier plots that represent survival (months) stratified by high/low miR-210 expression and high/low TNM stage. An association was observed between both high miR-210 expression and high TNM stage with decreased survival (log-rank 0.189 and 0.022 , respectively); however, the number of samples analysed in this study was too small for the miR-210 association to reach statistical significance. It should be noted that these are preliminary results and that additional confirmation of this result will now be required in other larger sets of renal cancers. In addition, it should be noted that in some renal tumours, HIF- $2 \alpha$ expression may dominate and therefore miR-210 may not provide general prognostic information for all cc RCC tumours.

\section{Expression of ISCU1/2 in cC RCC tumours}

The relationship between miR-210 levels and patient outcome suggests that miR-210 levels in cancer are not simply a marker of hypoxia but have a fundamental influence on tumour behaviour. To understand the mechanisms for the effects of miR-210 levels on patient outcome, we wished to study influences on potential mRNA targets. Computer-based algorithms are capable of predicting a large number of potential mRNA targets of particular miRNAs, some of which have been validated experimentally. We have defined a large number of potential miR-210 targets using such methodology, and during the course of this study Chan and colleagues [57] and subsequently others [58-60] were able to experimentally validate the regulation of one such predicted target, ISCU1/2. 


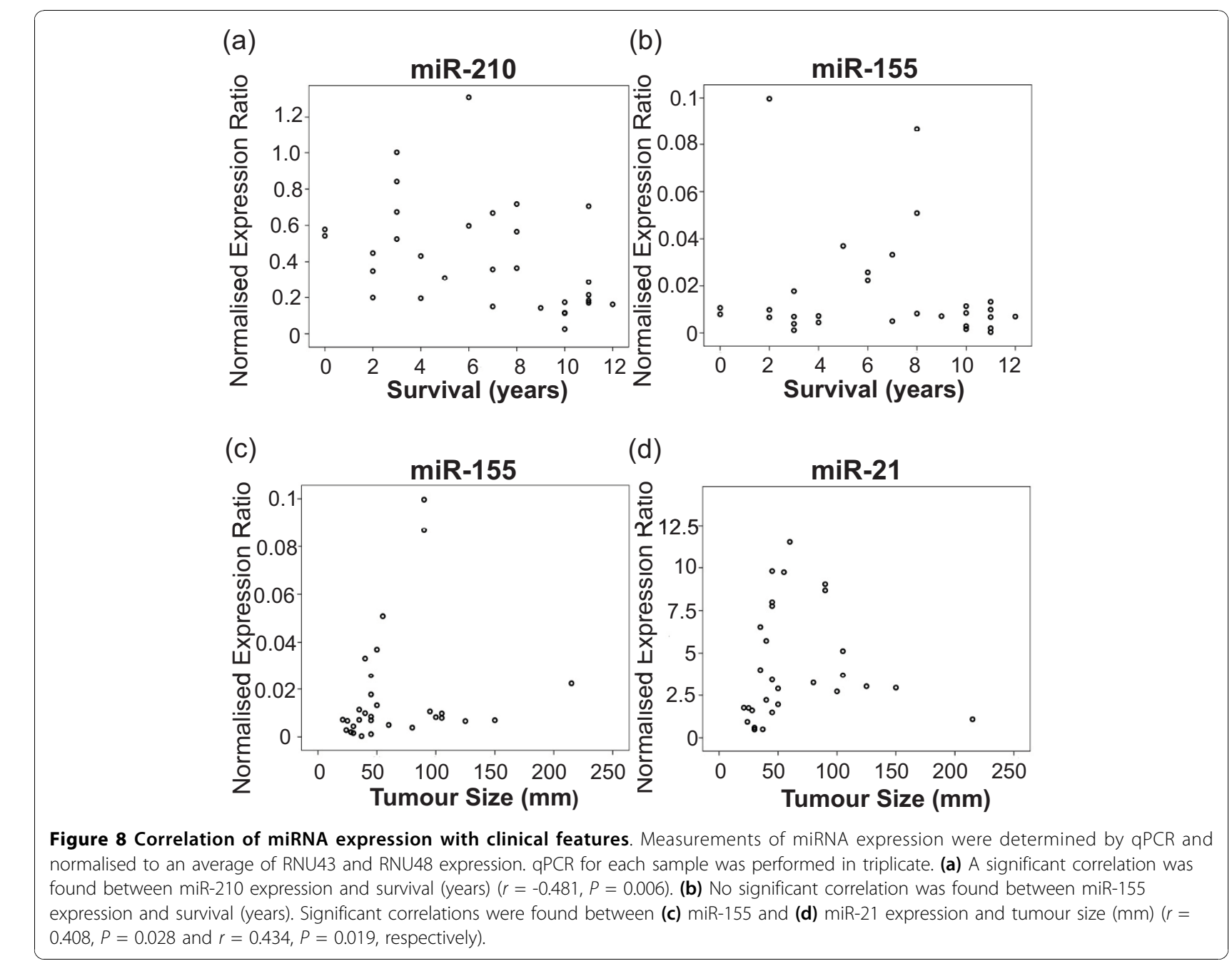

The iron cluster assembly proteins, ISCU1 and ISCU2, are involved in the biogenesis of [4Fe-4S] and [2Fe-2S] iron-sulfur clusters, which are implicated in a wide range of biological processes, including electron transport and mitochondrial oxidation-reduction reactions [61]. The ISCU protein exists as two splice isoforms in mammalian cells which share both structural and functional similarities: ISCU1 is located in the cytosol, whereas ISCU2 is located in the mitochondria [62]. It has been hypothesised that miR-210 represses the expression of ISCU1/2 during hypoxic conditions, thus disrupting mitochondrial function and causing downstream metabolic changes within the cell [57-60].

We sought to examine whether the elevation of miR210 levels in cc RCC was associated with reduced expression of ISCU1/2 mRNA. The expression of ISCU1/2 was analysed in the RCC4 \pm VHL cell lines, and it was found that the expression of ISCU1/2 was significantly reduced in the RCC4-VHL line by at least fivefold $(P=0.05)$ (Additional file 4), in keeping with targeting of ISCU1/2 by increased miR-210 expression. Consistent with this finding, a miR-210 mimic transfected into RCC4 + VHL cells to increase miR-210 levels did markedly decrease the mRNA expression of ISCU1/2 (threefold; $P=0.05$ ) (Additional file 5a). Likewise, a miR-210 antagomir transfected into RCC4-VHL cells to decrease miR-210 levels markedly increased the mRNA expression of ISCU1/2 (twofold; $P=0.05$ ) (Additional file $5 \mathrm{~b}$ ).

We therefore studied ISCU1/2 mRNA expression levels in the panel of renal cancers and found that, as previously shown, miR-210 expression is significantly upregulated in tumour tissue compared to normal adjacent tissue $(P \leq$ $0.0001)$, whereas an inverse expression pattern is observed for ISCU1/2 mRNA $(P \leq 0.0001)$ (Figure 10a). A striking negative correlation of miR-210 expression with ISCU1/2 mRNA in cc RCC tissue was observed, and, interestingly, this correlation was also observed in normal tissue $(r=$ $-0.679 ; P \leq 0.0001$ ) (Figure 10b). This suggests that miR-210 may be involved in the physiological regulation of ISCU1/2 expression levels in normal tissues, as well as in tumours, 

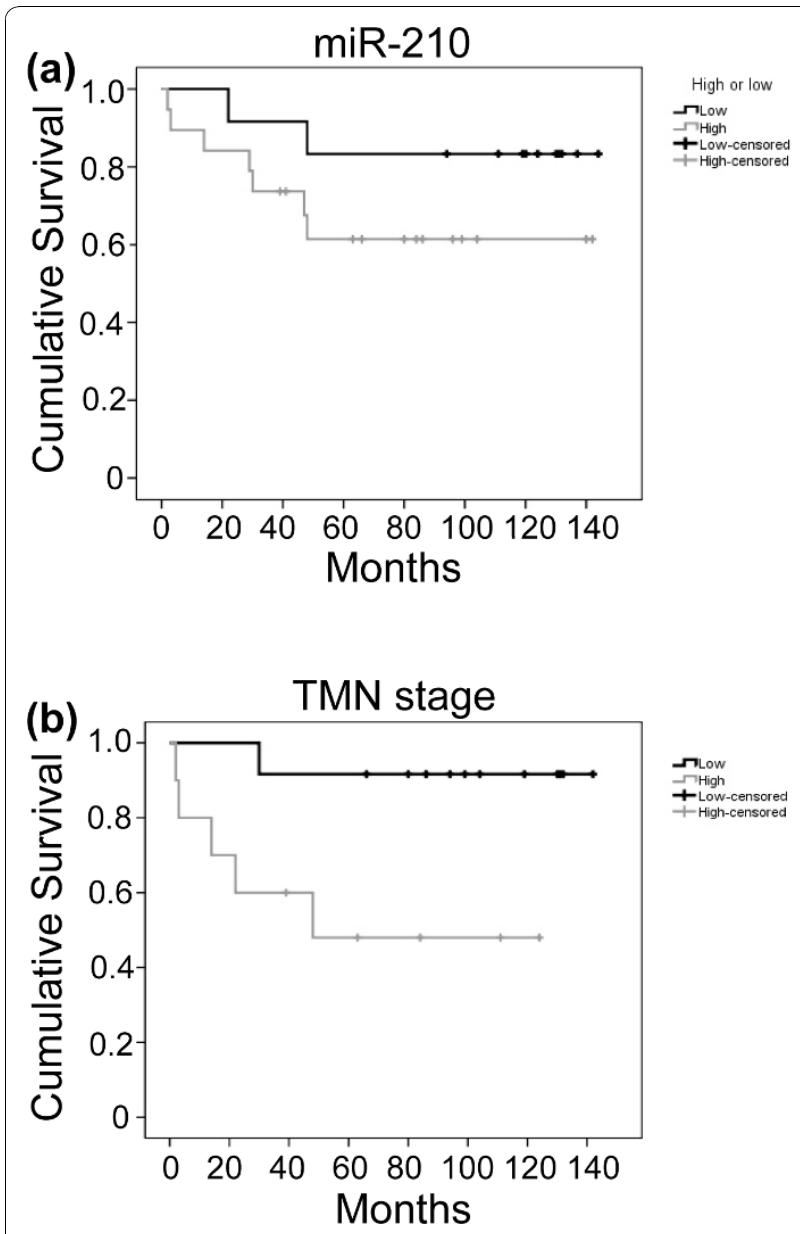

Figure 9 Overall survival is associated with miR-210 expression and tumour node metastasis (TNM) tumour stage. (a) KaplanMeier plot shows the overall survival of renal cancer patients stratified by high and low miR-210 expression levels. High expression is defined as above the maximum normal tissue expression value ( $P=0.189$; log rank). (b) Kaplan-Meier plot showing the overall survival of renal cancer patients stratified by low (Stages 1 and 2) and high (Stages 3 and 4) TNM stage cc RCC tumours ( $P=0.022$; log rank). The black line indicates low miR-210 expression or tumour stage, and the grey line indicates high miR210 expression or tumour stage.

and may contribute to the anaerobic pattern of respiration seen in renal (and other) tumours [63]. The levels of ISCU1/ 2 in renal cancers did not correlate with patient outcome, indicating that the influence of miR-210 level on patient survival is not mediated solely via ISCU1/2 regulation and that other miR-210 targets contribute to tumour aggression.

\section{Conclusions}

In this study, we have identified miRNAs which are regulated by VHL in cell culture. For some of these miRNAs, the regulation was HIF-dependent and for others it was HIF-independent. This pattern of regulation was also seen in cc RCC for some of these miRNAs when (a)

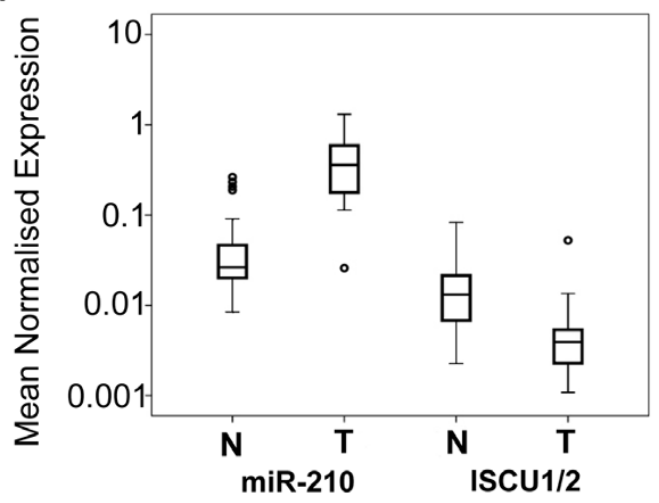

(b)

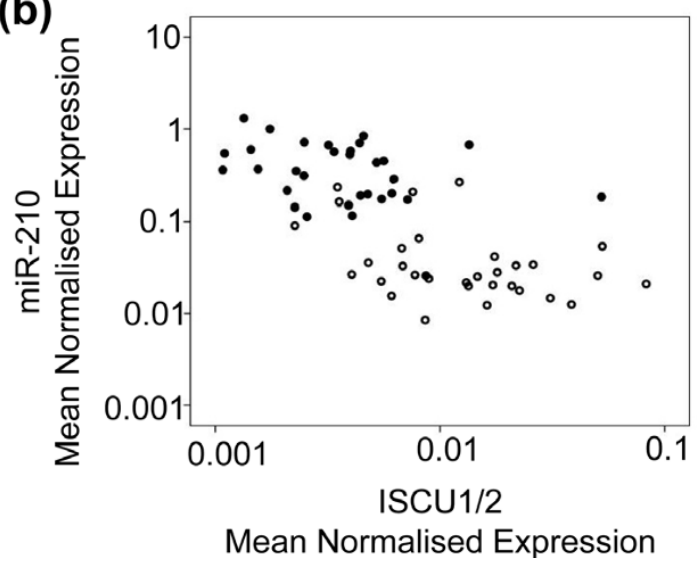

Figure 10 Expression of ISCU1/2 is negatively correlated with miR-210 expression. Measurements of ISCU1/2 and miR-210 expression were determined by $\mathrm{qPCR}$ and normalised to $\beta$-actin or an average of RNU43 and RNU48 expression. QPCR for each sample was performed in triplicate. (a) ISCU1/2 mRNA level is decreased in cC RCC tumours (T) compared to normal adjacent tissue (N) $(n=$ 31), whereas the inverse expression pattern is observed for miR-210 $(P \leq 0.0001)$. (b) A significant inverse correlation is observed between the miR-210 and ISCU1/2 expression level in both normal and tumour tissue $(r=-0.679, P \leq 0.0001)(n=62)$. Shaded circles indicate tumour tissue, and open circles represent adjacent normal tissue. Data are presented on $\log _{10}$ scales.

compared with normal adjacent renal tissue (miR-210, miR-155, let-7i and miR-18a). The level of one HIF- and VHL-regulated miRNA, miR-210, showed marked increases in expression in the renal cancer tissue, and expression levels were correlated inversely with patient survival. The enhanced levels of miR-210 in renal cancer are likely to be mediated by unrestrained HIF activity, independent of hypoxia. It suggests that the association that has been seen in other cancers between miR-210 levels and patient survival is not solely because it is a marker of tumour hypoxia, but because it influences tumour behaviour through alterations in gene expression. 
miR-210 levels also showed a correlation with a HIFregulated mRNA, CAIX, and with the presence of VHL mutation or promoter methylation. However, some tumours without evidence of VHL inactivation also had elevated miR-210 and CAIX levels, indicating the likely operation of other mechanisms of HIF activation. We also found a strong inverse correlation between miR-210 levels and mRNA expression of a miR-210 target gene, ISCU1/2, which may contribute to the repression of mitochondrial proteins by VHL and to the anaerobic pattern of respiration seen in renal (and other) tumours.

\section{List of abbreviations}

CAIX: Carbonic anhydrase IX; cc RCC: clear cell renal cell carcinoma; DMOG: dimethyloxalylglycine; HIF: hypoxia-inducible factor; ISCU1/2: Iron-sulfur cluster assembly protein; miRNA: microRNA; MSP: methylation specific PCR; qPCR: relative quantitation real-time PCR; RCC: renal cell carcinoma; siRNA: small interfering RNA; TNM: Tumour Node Metastasis; VHL: von Hippel-Lindau.

\section{Additional material}

Additional File 1: Protein expression of HIF-1 $\alpha$ and HIF- $2 \alpha$ in RCC4 \pm VHL cells and RCC4 + VHL cells treated with DMOG Immunoblot of cell extract obtained from RCC4 \pm VHL cells and RCC4 + VHL cells following DMOG treatment (1 mM, 24 hours). More HIF- $1 \alpha$ and HIF-2 $\alpha$ expression is seen in the RCC4-VHL cells and the DMOG treated RCC4 $+\mathrm{VHL}$ cells compared to RCC4 + VHL cells.

Additional File 2: CAIX expression in RCC4 \pm VHL cells and RCC4 + VHL cells treated with DMOG. Measurements of CAIX mRNA expression was determined by $\mathrm{qPCR}$ and normalised to $\beta$-actin mRNA expression. QPCR for each sample was performed in triplicate. Expression of CAIX was found to be increased in RCC4-VHL cells and RCC4 + VHL cells treated with DMOG (1 mM, 24 hours) compared to RCC4 + VHL cells ( $P$ $=0.05$ ).

\section{Additional File 3: Table S1. Summary of genetic changes found in}

VHL. The mutation nomenclature is in accordance with HGVS (Human Genome Variation Society) recommendations [31]. Nucleotide numbering is in accordance with GenBank mRNA sequence [GenBank:L15409] with the A of the first initiator ATG being 1. Previous descriptions of mutations were ascertained from http://www.umd.be[64], [33] and [65]. $\mathrm{N}^{*}$ indicates that precise mutation has not been reported; however, similar mutations involving the same codon have been described. Key: del-deletion, ins-insertion, MS-missense, FS- frameshift, N-nonsense, splsplice error.

Additional File 4: Expression of ISCU1/2 in RCC4+/-VHL cells Measurements of ISCU1/2 expression was determined by $\mathrm{QPCR}$ and normalised to $\beta$-actin mRNA expression. qPCR for each sample was performed in triplicate. (a) ISCU1/2 mRNA level is decreased in RCC4-VHL cells compared to RCC4 + VHL cells $(P=0.05)$.

\section{Additional File 5: Expression of ISCU1/2 following miR-210} overexpression and repression Measurements of ISCU1/2 expression were determined by $\mathrm{qPCR}$ and normalised to $\beta$-actin mRNA expression. QPCR for each sample was performed in triplicate. (a) ISCU1/2 expression level was decreased in RCC4+VHL cells transfected with a miR-210 mimic compared to untransfected RCC4 + VHL cells and RCC4 + VHL cells transfected with a negative control $(P=0.05)$. (b) ISCU1/2 expression level was increased in RCC4-VHL cells transfected with a miR-210 antagomir compared to untransfected RCC4-VHL cells and RCC4-VHL cells transfected with a negative control $(P=0.05)$.

\section{Acknowledgements}

This research was supported by a Research Establishment Award from the Don and Lorraine Jacquot Foundation administered by the Royal
Australasian College of Physicians. The authors thank Virginia Papangelis at the Flinders Medical Centre/Repatriation General Hospital tissue bank facility; Dr Richard Hummel, Department of Surgery, Flinders Medical Centre, for help with statistical analysis; Dr Ben Roberts, Division of Health Sciences, University of South Australia, for providing the RCC4-/+ VHL cell lines; and Belinda Mercorella, Department of Genetics and Molecular Pathology, IMVS, for assistance with $\mathrm{VHL}$ gene sequencing.

\section{Author details}

${ }^{1}$ Renal Unit, School of Medicine, Flinders University, Flinders Medical Centre, Adelaide, Australia. ${ }^{2}$ Department of Gastroenterology, School of Medicine, Flinders University, Flinders Medical Centre, Adelaide, Australia. ${ }^{3}$ Familial Cancer Section, Department of Genetics and Molecular Pathology, IMVS, Adelaide, Australia. ${ }^{4}$ Adelaide Microarray Centre, School of Molecular and Biomedical Sciences, University of Adelaide, Adelaide, Australia.

\section{Authors' contributions}

CSN performed the experiments, undertook statistical analysis and drafted the paper.

MZM supervised the experiments, participated in the design of the study and drafted the paper. LHR designed and analysed the VHL molecular genetic studies. MBVdH coordinated and analysed the microarray experiments. JMG designed the study, supervised the experiments and drafted the paper. All authors read and approved the final manuscript.

\section{Competing interests}

JMG is an inventor on a patent seeking to utilise miRNA expression as a prognostic marker in cancer. MZM is an inventor on a patent (pending) for technology that exploits differential miRNA expression to regulate the expression of therapeutic transgenes.

Received: 21 September 2010 Accepted: 21 October 2010 Published: 21 October 2010

\section{References}

1. Rini BI, Campbell SC, Escudier B: Renal cell carcinoma. Lancet 2009, 373:1119-1132.

2. Kim WY, Kaelin WG: Role of VHL gene mutation in human cancer. J Clin Oncol 2004, 22:4991-5004.

3. Maher ER: von Hippel-Lindau disease. Curr Mol Med 2004, 4:833-842.

4. Harris A: Hypoxia: a key regulatory factor in tumour growth. Nat Rev Cancer 2002, 2:38-47.

5. Gleadle JM: Review article: how cells sense oxygen: lessons from and for the kidney. Nephrology 2009, 14:86-93.

6. Epstein ACR, Gleadle JM, McNeill LA, Hewitson KS, O'Rourke J, Mole DR, Mukherji M, Metzen E, Wilson MI, Dhanda A, Tian YM, Masson N, Hamilton DL, Jaakkola P, Barstead R, Hodgkin J, Maxwell PH, Pugh CW, Schofield CJ, Ratcliffe PJ: C. elegans EGL-9 and mammalian homologs define a family of dioxygenases that regulate HIF by prolyl hydroxylation. Cell 2001, 107:43-54.

7. Elvidge GP, Glenny L, Appelhoff RJ, Ratcliffe PJ, Ragoussis J, Gleadle JM: Concordant regulation of expression by hypoxia and 2-oxoglutaratedependent dioxygenase inhibition. J Biol Chem 2006, 281:15215-15226.

8. Semenza GL: Targeting HIF-1 for cancer therapy. Nat Rev Cancer 2003, 3:721-732.

9. Frew IJ, Krek W: pVHL: a multipurpose adaptor protein. Sci Signal 2008, 1: pe30.

10. Kenneth NS, Rocha S: Regulation of gene expression by hypoxia. Biochem J 2008, 414:19-29.

11. Lu J, Getz G, Miska EA, Alvarez-Saavedra E, Lamb J, Peck D, SweetCordero A, Ebert BL, Mak RH, Ferrando AA, Downing JR, Jacks T, Horvitz HR, Golub TR: MicroRNA expression profiles classify human cancers. Nature 2005, 435:834-838.

12. Volinia S, Calin G, Liu C, Ambs S, Cimmino A, Petrocca F, Visone R, lorio M, Roldo C, Ferracin M, Prueitt RL, Yanaihara N, Lanza G, Scarpa A, Vecchione A, Negrini M, Harris CC, Croce CM: A microRNA expression signature of human solid tumors defines cancer gene targets. Proc Natl Acad Sci USA 2006, 103:2257-2261.

13. He L, Thomson M, Hemann MT, Hernando-Monge E, Mu D, Goodson Summer, Powers S, Cordon-Cardo C, Lowe SW, Hannon GJ, 
Hammond SM: A microRNA polycistron as a potential human oncogene. Nature 2005, 435:828-833.

14. O'Donnell KA, Wentzel EA, Zeller KI, Dang CV, Mendell JT: c-Myc-regulated microRNAs modulate E2F1 expression. Nature 2005, 435:839-843.

15. Sassen S, Miska EA, Caldas C: MicroRNA: implications for cancer. Virchows Arch 2008, 452:1-10.

16. Wang Y, Lee CGL: MicroRNA and cancer: focus on apoptosis. J Cell Mol Med 2009, 13:12-23.

17. Suzuki HI, Yamagata $K$, Sugimoto K, Iwamoto $T$, Kato S, Miyazono K: Modulation of microRNA processing by p53. Nature 2009, 460:529-534

18. Horikawa Y, Wood CG, Yang H, Zhao H, Ye Y, Gu J, Lin J, Habuchi T, Wu X: Single nucleotide polymorphisms of microRNA machinery genes modify the risk of renal cell carcinoma. Clin Cancer Res 2008, 14:7956-7962.

19. Camps C, Buffa FM, Colella S, Moore J, Sheldon H, Harris AL, Gleadle JM, Ragoussis J: hsa-miR-210 is induced by hypoxia and is an independent prognostic factor in breast cancer. Clin Cancer Res 2008, 14:1-8.

20. Gee HE, Camps C, Buffa FM, Colella S, Sheldon H, Gleadle JM, Ragoussis J, Harris AL: MicroRNA-10b and breast cancer metastasis. Nature 2008, 455 E8-E9.

21. Jung M, Mollenkopf HJ, Grimm C, Wagner I, Albrecht M, Waller T, Pilarsky C, Johannsen M, Stephan C, Lehrach H, Nietfeld W, Rudel T, Jung K, Kristiansen G: MicroRNA profiling of clear cell renal cell cancer identifies a robust signature to define renal malignancy. J Cell Mol Med 2009, 13:3918-3928.

22. Chow TF, Youssef YM, Lianidou E, Romaschin AD, Honey RJ, Stewart R, Pace KT, Yousef GM: Differential expression profiling of microRNAs and their potential involvement in renal cell carcinoma pathogenesis. Clin Biochem 2010, 43:150-158.

23. Nakada C, Matsuura K, Tsukamoto T, Tanigawa M, Yoshimoto Y, Narimatsu T, Ngugen L, Hiijya N, Uchida T, Sato F, Mimata H, Seto M, Moriyama M: Genome-wide microRNA expression profiling in renal cell carcinoma: significant down regulation of miR-141 and miR-200c. $\rfloor$ Pathol 2008, 216:418-427.

24. Maxwell $P$, Wiesener M, Chang G, Clifford S, Vaux EC, Cockman M, Wykoff CC, Pugh C, Maher E, Ratcliffe P: The tumour suppressor protein VHL targets hypoxia inducible factors for oxygen-dependent proteolysis. Nature 1999, 399:271-275.

25. Asikainen TM, Schneider BK, Waleh NS, Clyman RI, Ho WB, Flippin LA, Gunzler V, White CW: Activation of hypoxia-inducible factors in hyperoxia through prolyl 4-hydroxylase blockade in cells and explants of primate lung. Proc Natl Acad Sci USA 2005, 102:10212-10217.

26. Jaakkola P, Mole DR, Tian YM, Wilson MI, Gielbert J, Gaskell SJ, Kriegsheim Av, Hebestreit HF, Mukherji M, Schofield CJ, Maxwell PH, Pugh CW, Ratcliffe PJ: Targeting of HIF-alpha to the von Hippel-Lindau ubiquitylation complex by $\mathrm{O}_{2}$-regulated prolyl hydroxylation. Science 2001, 292:468-472.

27. Thomson JM, Parker J, Perou CM, Hammond SM: A custom microarray platform for analysis of microRNA gene expression. Nat Methods 2004, 1:47-53.

28. Smyth G: Linear models and empirical Bayes methods for assessing differential expression in microarray experiments. Stat Appl Genet Mol Biol 2004, 3, Article 3.

29. Pfaffl MW, Horgan GW, Dempfle L: Relative Expression Software Tool (REST) for group-wise comparison and statistical analysis of relative expression results in real-time PCR. Nucl Acids Res 2002, 30:E36.

30. Hong S, Furihata M, Baba M, Zbar B, Schmidt L: Vascular defects and liver damage by the acute inactivation of the VHL gene during mouse embryogenesis. Lab Invest 2006, 86:664-675.

31. den Dunnen JT, Antonarakis SE: Mutation nomenclature extensions and suggestions to describe complex mutations: a discussion. Hum Mutat 2000, 15:7-12.

32. Herman JG, Graff JR, Myohanen S, Nelkin BD, Baylin SB: Methylationspecific PCR: a novel PCR assay for methylation status of $\mathrm{CpG}$ islands. Proc Natl Acad Sci USA 1996, 93:9821-9826.

33. Banks RE, Tirukonda P, Taylor C, Hornigold N, Astuti D, Cohen D, Maher ER, Stanley AJ, Harnden P, Joyce A, Knowles M, Selby PJ: Genetic and epigenetic analysis of von Hippel-Lindau (VHL) gene alterations and relationship with clinical variables in sporadic renal cancer. Cancer Res 2006, 66:2000-2011.
34. Gleadle J, Ebert B, Firth J, Ratcliffe P: Regulation of angiogenic growth factor expression by hypoxia, transition metals, and chelating agents. Am J Physiol 1995, 268:C1362-C1368.

35. Pradervand S, Weber J, Thomas J, Bueno M, Wirapati P, Lefort K, Dotto GP, Harshman K: Impact of normalization on miRNA microarray expression profiling. RNA 2009, 15:493-501.

36. Selcuklu SD, Donoghue MTA, Spillane C: miR-21 as a key regulator of oncogenic processes. Biochem Soc Trans 2009, 37:918-925.

37. Chow TF, Mankaruos M, Scorilas A, Youssef Y, Girgis A, Mossad S, Metias S, Rofael Y, Honey RJ, Stewart R, Pace KT, Yousef GM: The miR-17-92 cluster is over expressed in and has an oncogenic effect on renal cell carcinoma. J Urol 2010, 183:743-751.

38. Gironella M, Seux M, Xie MJ, Cano C, Tomasini R, Gommeaux J, Garcia S, Nowak J, Yeung ML, Jeang KT, Chaix A, Fazli L, Motoo Y, Wang Q, Rocchi P, Russo A, Gleave M, Dagorn JC, lovanna JL, Carrier A, Pébusque MJ, Dusetti NJ: Tumor protein 53-induced nuclear protein 1 expression is repressed by miR-155, and its restoration inhibits pancreatic tumor development. Proc Natl Acad Sci USA 2007, 104:16170-16175.

39. O'Connell RM, Chaudhuri AA, Rao DS, Baltimore D: Inositol phosphatase SHIP1 is a primary target of miR-155. Proc Natl Acad Sci USA 2009, 106:7113-7118.

40. Hayashita Y, Osada H, Tatematsu Y, Yamada H, Yanagisawa K, Tomida S, Yatabe Y, Kawahara K, Sekido Y, Takahashi T: A polycistronic microRNA cluster, miR-17-92, is overexpressed in human lung cancers and enhances cell proliferation. Cancer Res 2005, 65:9628-9632.

41. Taguchi A, Yanagisawa K, Tanaka M, Cao K, Matsuyama Y, Goto H, Takahashi T: Identification of hypoxia-inducible factor-1a as a novel target for miR-17-92 microRNA cluster. Cancer Res 2008, 68:5540-5545.

42. Suarez YC, Fernandez-Hernando C, YU J, Gerber SA, Harrison KD, Pober JS, Iruela-Arispe ML, Merkenschlager M, Sessa WC: Dicer-dependent endothelial microRNAs are necessary for postnatal angiogenesis. Proc Natl Acad Sci USA 2008, 105:14082-14087.

43. Tagawa H, Karube K, Tsuzuki S, Ohshima K, Seto M: Synergistic action of the microRNA-17 polycistron and Myc in aggressive cancer development. Cancer Sci 2007, 98:1482-1490.

44. Woods K, Thomson J, Hammond S: Direct regulation of an oncogenic micro-RNA cluster by E2F transcription factors. J Biol Chem 2006, 282:2130-2134.

45. Dews M, Homayouni A, Yu D, Murphy D, Sevignani C, Wentzel E, Furth E, Lee W, Enders G, Mendell J, Thomas-Tikhonenko A: Augmentation of tumor angiogenesis by a Myc-activated microRNA cluster. Nat Genet 2006, 38:1060-1065.

46. Brueckner B, Stresemann C, Kuner R, Mund C, Musch T, Meister M, Sultmann H, Lyko F: The human let-7a-3 locus contains an epigenetically regulated microRNA gene with oncogenic function. Cancer Res 2007, 67:1419-1423.

47. Iorio MV, Ferracin M, Liu CG, Veronese A, Spizzo R, Sabbioni S, Magri E, Pedriali M, Fabbri M, Campiglio M, Ménard S, Palazzo JP, Rosenberg A, Musiani P, Volinia S, Nenci I, Calin GA, Querzoli P, Negrini M, Croce CM: MicroRNA gene expression deregulation in human breast cancer. Cancer Res 2005, 65:7065-7070.

48. Hebert C, Norris K, Scheper M, Nikitakis N, Sauk J: High mobility group A2 is a target for miRNA-98 in head and neck squamous cell carcinoma. Mol Cancer 2007, 6:5.

49. Yang N, Kaur S, Volinia S, Greshock J, Lassus H, Hasegawa K, Liang S, Leminen A, Deng S, Smith L, Johnstone CN, Chen XM, Liu CG, Huang Q, Katsaros D, Calin GA, Weber BL, Bützow R, Croce CM, Coukos G, Zhang L: MicroRNA microarray identifies Let-7i as a novel biomarker and therapeutic target in human epithelial ovarian cancer. Cancer Res 2008, 68:10307-10314.

50. Loncaster J, Harris A, Davidson S, Logue J, Hunter R, Wycoff C, Pastorek J, Ratcliffe P, Stratford I, West C: CAIX expression, a potential new intrinsic marker of hypoxia: correlations with tumour oxygen measurements and prognosis in locally advanced carcinoma of the cervix. Cancer Res 2001, 61:6394-6399.

51. Leibovich BC, Sheinin Y, Lohse CM, Thompson RH, Cheville JC, Zavada J, Kwon ED: Carbonic anhydrase IX is not an independent predictor of outcome for patients with clear cell renal cell carcinoma. J Clin Oncol 2007, 25:4757-4764.

52. Nickerson ML, Jaeger E, Shi Y, Durocher JA, Mahurkar S, Zaridze D, Matveev V, Janout V, Kollarova H, Bencko V, Navratilova M, Szeszenia- 
Dabrowska N, Mates D, Mukeria A, Holcatova I, Schmidt LS, Toro JR, Karami S, Hung R, Gerard GF, Linehan WM, Merino M, Zbar B, Boffetta P, Brennan P, Rothman N, Chow WH, Waldman FM, Moore LE: Improved identification of von Hippel-Lindau gene alterations in clear cell renal tumors. Clin Cancer Res 2008, 14:4726-4734.

53. Smits KM, Schouten LJ, van Dijk BA, Hulsbergen-van de Kaa CA, Wouters KA, Oosterwijk E, van Engeland M, van den Brandt PA: Genetic and epigenetic alterations in the von Hippel-Lindau gene: the influence on renal cancer prognosis. Clin Cancer Res 2008, 14:782-787.

54. Dalgliesh GL, et al: Systematic sequencing of renal carcinoma reveals inactivation of histone modifying genes. Nature 2010, 463:360-363.

55. Ghosh AK, Shanafelt TD, Cimmino A, Taccioli C, Volinia S, Liu Cg, Calin GA, Croce CM, Chan DA, Giaccia AJ, Secreto C, Wellik LE, Lee YK, Mukhopadhyay D, Kay NE: Aberrant regulation of pVHL levels by microRNA promotes the HIF/VEGF axis in CLL B cells. Blood 2009, 113:5568-5574.

56. Gee HE, Camps C, Buffa FM, Patiar S, Winter SC, Betts G, Homer J, Corbridge R, Cox G, L.West CM, Ragoussis J, Harris AL: hsa-mir-210 is a marker of tumor hypoxia and a prognostic factor in head and neck cancer. Cancer 2010, 116:2148-2158.

57. Chan SY, Zhang YY, Hemann C, Mahoney CE, Zweier JL, Loscalzo J: MicroRNA-210 controls mitochondrial metabolism during hypoxia by repressing the iron-sulfur cluster assembly proteins ISCU1/2. Cell Metab 2009, 10:273-284.

58. Favaro E, Ramachandran A, McCormick R, Gee H, Blancher C, Crosby M, Devlin C, Blick C, Buffa F, Li JL, Vojnovic B, Pires das Neves R, Glazer P, Iborra F, Ivan M, Ragoussis J, Harris AL: MicroRNA-210 regulates mitochondrial free radical response to hypoxia and Krebs cycle in cancer cells by targeting iron sulfur cluster protein ISCU. PLoS One 2010, 5:e1034.

59. Fasanaro P, Greco S, Lorenzi M, Pescatori M, Brioschi M, Kulshreshtha R, Banfi C, Stubbs A, Calin GA, Ivan M, Capogrossi MC, Martelli F: An integrated approach for experimental target identification of hypoxiainduced miR-210. J Biol Chem 2009, 284:35134-35143.

60. Chen Z, Li Y, Zhang H, Huang P, Luthra R: Hypoxia-regulated microRNA210 modulates mitochondrial function and decreases ISCU and COX10 expression. Oncogene 2010, 29:4362-4368.

61. Rouault TA, Tong WH: Iron-sulfur cluster biogenesis and human disease. Trends Genet 2008, 24:398-407.

62. Tong WH, Rouault $\mathrm{T}$ : Distinct iron-sulfur cluster assembly complexes exist in the cytosol and mitochondria of human cells. EMBO J 2000, 19:5692-5700

63. Hsu PP, Sabatini DM: Cancer cell metabolism: Warburg and beyond. Cell 2008, 134:703-707.

64. Béroud C, Joly D, Gallou C, Staroz F, Orfanelli M, Junien C: Software and database for the analysis of mutations in the VHL gene. Nucl Acids Res 1998, 26:256-258.

65. Nordstrom-O'Brien $M$, van der Luijt $R B$, van Rooijen $E$, van den Ouweland AM, Majoor-Krakauer DF, Lolkema MP, van Brussel A, Voest EE, Giles RH: Genetic analysis of von Hippel-Lindau disease. Hum Mutat 2010, 31:521-537.

\section{Pre-publication history}

The pre-publication history for this paper can be accessed here: http://www.biomedcentral.com/1741-7015/8/64/prepub

\section{doi:10.1186/1741-7015-8-64 \\ Cite this article as: Neal et al:: The VHL-dependent regulation of microRNAs in renal cancer. BMC Medicine 2010 8:64.}

\section{Submit your next manuscript to BioMed Central and take full advantage of:}

- Convenient online submission

- Thorough peer review

- No space constraints or color figure charges

- Immediate publication on acceptance

- Inclusion in PubMed, CAS, Scopus and Google Scholar

- Research which is freely available for redistribution

Submit your manuscript at www.biomedcentral.com/submit
Biomed Central 